Sneath, P. H. A. \& Cowan, S. T. (1958). J. gen. Microbiol. 19, 551-565

\title{
An Electro-Taxonomic Survey of Bacteria
}

\author{
By P. H. A. SNEATH and S. T. COWAN \\ National Institute for Medical Research, Mill Hill, London, N.W. 7 and \\ National Collection of Type Cultures, Central Public Health Laboratory, \\ London, N.W. 9
}

SUMMARY: A taxonomic survey of a wide range of bacteria has been made with the aid of an electrical computing machine. The strains examined fell into five main groups: (1) Gram-positive organisms, including streptococci, micrococci, staphylococci, Aerococcus, Erysipelothrix, Listeria and certain diphtheroids; (2) predominantly Gram-negative organisms, including enterobacteria, pseudomonads Pasteurella, Vibrio, Actinobacillus, Loefferella, Brucella, Neisseria, Chromobacterium and also Bacillus; (3) Corynebacterium diphtheriae; (4) acid-fast bacilli; (5) spirilla.

Within group 1 were subgroups representing Streptococcus, Micrococcus and Staphylococcus. Within group 2 were subgroups representing: $(a)$ most enterobacteria together with Pasteurella pestis and Vibrio; (b) Brucella, Neisseria, Actinobacillus lignieresi, Pasteurella septica and possibly also Shigella; (c) pseudomonads; (d) Bacillus; (e) Chromobacterium violaceum and $(f)$ Proteus.

The taxonomy suggested by this study is compared with that in current use. Temporary working type strains of most of the species are suggested for use in surveys of this kind. The limitations of the method and of using old laboratory records are discussed.

A method of classifying bacteria has been proposed by which an electronic computer is used to indicate the main taxonomic groupings (Sneath, $1957 a$, b). The method is based on the Adansonian principles: (1) that every feature is of equal importance in creating taxa; (2) that organisms are classified upon their overall similarity to one another; (3) that overall similarity is the proportion of features possessed in common by two organisms; (4) that divisions between taxa are based on correlated features. These principles follow from the concept that an ideal taxonomy is one containing the greatest content of information in its taxa. An index $(S)$ of overall similarity was proposed, equal to $n_{s} /\left(n_{s}+n_{d}\right)$, where $n_{s}$ was the number of positive features possessed by both of two organisms, and $n_{d}$ was the number of features possessed by one organism and not the other and vice versa. The definition of a feature and the method of analysis were also given.

It was suggested that a survey of a wide range of bacteria might be made, and, since $S$ could be a guide to the taxonomic rank, under certain conditions it could be used to define it. Such a survey might enable a revision of the classification of the Schizomycetes to be made. The present paper is an account of such a survey, but it is emphasized that we do not propose any taxonomic revisions here, since we feel that the results are inadequate for such revision. The purpose of the present paper is to indicate the limitations of using old laboratory records, to suggest strains which might be used as reference strains 
in future surveys and to indicate the lines along which more detailed work might profitably be done.

The most important contribution which can be made in a preliminary study like this is to suggest reference strains for future work, since the method requires that if two surveys are to be validly compared then several of the same bacterial strains must be included in both surveys. Ideally these strains would be the type strains of the taxa studied, but in most taxa type strains do not exist, either because they have been lost or because they were never designated. The Judicial Commission of the International Committee on Bacteriological Nomenclature is empowered to establish new type strains where they do not exist, but since the Commission requires that a taxon must be well studied before a neotype is established, for most taxa this will doubtless take many years, if indeed the taxa can be well studied at all without resource to type strains of some sort. We have, therefore, felt it best to break the vicious circle by suggesting certain strains as temporary working type strains for studies of this kind, and some of them may in due course be proposed as neotypes for approval by the Commission. These strains were chosen as typical of the species they represented, and most of them are described in the Collection Catalogue (National Collection of Type Cultures: Catalogue of Species, 1958). It should be noted that a type strain need not be typical in every respect (International Code of Nomenclature of Bacteria and Viruses, 1958, note to Principle 11), although it must not be 'based upon an abnormality' (Rule 24(h)) - the distinction is a nice one. Indeed the more tests used the more difficult it is to find any strain which is not atypical in some respect. We have therefore not hesitated to use our own judgement in doubtful instances, although we are aware that some choices will precipitate much argument among experts on the taxa concerned-e.g. Pasteurella pestis NCTC 5923 is an avirulent strain chosen for ease and safety of handling. We are much indebted to many colleagues for advice on whether strains are typical, though it has unfortunately not been possible to refer every strain to an acknowledged expert for an opinion.

The importance of type strains is that they determine the application of names whenever taxa are rearranged. Thus, the genus Bacillus is by definition composed of those organisms which (in the opinion of an author) belong to the same genus as the type species Bacillus subtilis, and hence belong to the same genus as the type strain of $B$. subtilis which is NCTC 3610 (in this instance a neotype, see St John-Brooks \& Breed, 1937). If the genus is split into two genera, then Bacillus must be retained for the section to which the type belongs. This reference to types extends in practice at any rate up to familiese.g. Bacillaceae means 'the Bacillus family'. There are various names for types used in botany which indicate different degrees of reliability when a type has not been designated. One nomenclature is given by Ciferri (1957), but his terms apply to strains of the author who named the taxon; this seems to be a doubtful point, for under the Bacteriological Code it would seem more correct for them to apply to strains of the author of the description on which the taxon is based (who need not be the author of the name). The 
nomenclature used here is based on the convenient nomenclature of Ainsworth \& Bisby (1945).

Holotype. The designated type strain. This takes precedence over any other. If the taxon is based on the description of only one strain this strain would be the holotype by monotypy.

Paratype. Any specimen (other than the holotype) which is specifically stated as being one of the strains on which the original description of the taxon was based (compare Cotype and Isotype).

Cotype. Any specimen of the describing author's collection if he did not designate a holotype strain.

Isotype. Any specimen of the describing author's collection (other than the holotype) when he did designate a holotype strain.

Lectotype. A type taken later for a group for which the author did not designate a type.

Neotype. A type established by the Judicial Commission to replace a designated type which has been lost, or for a group for which a type was not designated. Many neotypes are also lectotypes.

A second reason for publishing this survey is that it is of interest to see what accuracy is attainable with data obtained by standardized methods but read by different observers at different times. The accuracy is clearly less than that of a deliberate comparative study at one time, but may yield useful suggestions for closer study, and large collections of laboratory data must exist which could be used for this purpose.

Validity of the comparisons. In a survey of this kind which uses a wide range of bacteria it is not easy to obtain strictly comparable data. Thus, we cannot make a strictly valid comparison between a strict thermophil and a strict psychrophil, since there is no temperature at which both will grow. We may compare them indirectly by comparing each with a bacterium which is facultatively both thermophilic and psychrophilic. If this is not practicable we must grant the unproved assumption that the growth temperature does not greatly affect the expression of features. This is not an unreasonable assumption (e.g. if we obtained a mesophilic mutant of a thermophilic Bacillus we should be unlikely to find that it possessed all the features of a typical Micrococcus), but such assumptions must be clearly stated and kept to the minimum. For this reason we have excluded the strictly anaerobic forms (Clostridium) from the figures and have added the conclusions in the text only. In the routine practice of the National Collection of Type Cultures the organisms are tested at temperatures near their optimum temperatures, all in the range of $20^{\circ}-37^{\circ}$, and perforce (without repeating all the work) we have had to assume that this makes little difference to the taxonomic conclusions, though it is not strictly valid. This, and a small number of instances where serum and other adjuvants are necessary to obtain growth in routine peptone or meat extract media, or where the sodium chloride concentration must be decreased, are the only ones where the comparisons are not strictly valid, but there are good reasons for thinking that these factors will not in general greatly influence the features; where there is doubt the data have not been used. 


\title{
METHODS
}

\author{
Scope of the survey
}

The National Collection of Type Cultures specializes in bacteria of medical and veterinary interest. This means that some well-known taxa are not represented (e.g. Rhizobium), but since bacteria of medical and veterinary importance have as a rule been more thoroughly studied than the others it is not an unsuitable collection for a review of this kind, and in the event of taxonomic revision the nomenclatural types will generally be included in this collection.

In Table 1 are listed the strains used in this survey, with their type status. We have included all designated type strains possessed by the Collection. In Table 2 are shown the relevant parts of the classification used in Bergey's Manual (7th edition, 1957), together with the type status of the taxa.

\section{Table 1. Particulars of strains and of their type status}

The names are those used in the Catalogue of the Collection (The National Collection of Type Cultures: Catalogue of Species, 1958), with a few exceptions. The citations of authors will be found in the Catalogue or in Bergey's Manual, 7th edition (1957), but they have been given here if the species is not widely known or if confusion might otherwise arise. The name used in Bergey's Manual is added in brackets when it is different from that used in the Catalogue. If the species is generally accepted as the type species of the genus the letters T.Sp. have been added.

\begin{tabular}{|c|c|c|}
\hline $\begin{array}{l}\text { Number in } \\
\text { Fig. } 1\end{array}$ & $\begin{array}{l}\text { NCTC } \\
\text { number }\end{array}$ & Species \\
\hline 1 & 5224 & Corynebacterium pyogenes \\
\hline 2 & 7564 & Staphylococcus lactis (Shaw et al. 1951)* \\
\hline $\mathbf{3}$ & 8163 & Erysipelothrix rhusiopathiae T.Sp. (E. insidiosa) \\
\hline 4 & 8198 & Streptococcus pyogenes, Lancefield group A, T.Sp. \\
\hline $\mathbf{5}$ & 8191 & Streptococcus pyogenes, Lancefield group A, T.Sp. \\
\hline 6 & 7760 & Streptococcus sp., group M \\
\hline 7 & 8251 & Aerococcus viridans (Williams et al. 1953), T.Sp.* \\
\hline 8 & 8029 & Streptococcus sp., group O \\
\hline 9 & 8512 & Micrococcus luteus T.Sp. \\
\hline 10 & 2416 & Chromobacterium viscosum (Grimes, 1927) $\dagger^{*}$ \\
\hline 11 & 2665 & Staphylococcus afermentans (Shaw et al. 1951)* \\
\hline 12 & 7973 & Listeria monocytogenes T.Sp. \\
\hline 13 & 8532 & Staphylococcus aureus T.Sp. \\
\hline 14 & 7292 & Staphylococcus saprophyticus (S. epidermidis) \\
\hline 15 & 8384 & Salmonella typhi (S. typhosa) \\
\hline 16 & 8385 & Salmonella typhi (S. typhosa) \\
\hline 17 & $\mathbf{5 7 3 5}$ & Salmonella choleraesuis T.Sp. \\
\hline 18 & 9001 & Escherichia coli T.Sp. \\
\hline 19 & 9002 & Escherichia coli T.Sp. \\
\hline 20 & 86 & Escherichia coli T.Sp. \\
\hline 21 & 5923 & Pasteurella pestis \\
\hline 22 & 5924 & Pasteurella pestis \\
\hline 23 & 9493 & Serratia marcescens T.Sp. \\
\hline 24 & 1377 & Serratia marcescens $\mathbf{T}$. Sp. \\
\hline 25 & 8457 & Vibrio sp., El Tor variety \\
\hline 26 & 8021 & Vibrio choleraeasiaticae (V.comma) T.Sp. \\
\hline
\end{tabular}

Type status of strain
TWT
Holotype
TWT
TWT
Holotype -
Proposed neotype (Breed,
1952), TWT
Holotype
Holotype
Paratype, TWT
Proposed neotype (Cowan
et al. 1954), TWT
Proposed neotype (Shaw
et al. 1951), TWT
TWT -
TWT -
Proposed neotype (Entero-
bacteriaceae subcommittee)
TWT -
Cotype -
TWT -
TWT




\begin{tabular}{|c|c|c|c|}
\hline \multirow[b]{2}{*}{$\begin{array}{l}\text { Number in } \\
\text { Fig. } 1\end{array}$} & \multicolumn{2}{|r|}{ Table 1 (cont.) } & \multirow[b]{2}{*}{ Type status of strain } \\
\hline & $\begin{array}{l}\text { NCTC } \\
\text { number }\end{array}$ & Species & \\
\hline 27 & 7254 & Vibrio choleraeasiaticae (V. comma) T.Sp. & TWT \\
\hline 28 & 5055 & Klebsiella pneumoniae T.Sp. & TW'T \\
\hline $\mathbf{2 9}$ & 8016 & Loefflerella pseudomallei (Pseudomonas pseudomallei) & - \\
\hline 30 & 3195 & Pasteurella septica (P. multocida) & TWT \\
\hline $\mathbf{8 1}$ & 4976 & Actinobacillus lignieresi (A. lignieresii) T.Sp. & TWT \\
\hline 32 & 4189 & Actinobacillus lignieresi (A. lignieresii) T.Sp. & - \\
\hline 33 & 7470 & Brucella melitensis T.Sp. & TWT \\
\hline 34 & 8223 & Brucella melitensis T.Sp. & - \\
\hline 35 & 8375 & Neisseria gonorrhoeae T.Sp. & TWT \\
\hline 36 & 4837 & Shigella dysenteriae, Type 1 (Shiga's bacillus) T.Sp. & TWT \\
\hline 37 & 6750 & Pseudomonas aeruginosa T.Sp. & TWT \\
\hline 38 & 2000 & Pseudomonas aeruginosa T.Sp. & - \\
\hline 39 & 1691 & Loefflerella pseudomallei (Pseudomonas pseudomallei) & - \\
\hline 40 & $\mathbf{3 6 1 0}$ & Bacillus subtilis T.Sp., Marburg strain & $\begin{array}{l}\text { Neotype (St John-Brooks \& } \\
\text { Breed, 1937) }\end{array}$ \\
\hline 41 & 6276 & Bacillus subtilis T.Sp. & - \\
\hline 42 & 8162 & Bacillus pantothenticus & Holotype \\
\hline 43 & 7464 & Bacillus cereus & TWT \\
\hline 44 & 9757 & $\begin{array}{l}\text { Chromobacterium violaceum nom. prop. conserv. } \\
\text { T.Sp. (Sneath, 1956) (C. janthinum) } \ddagger\end{array}$ & $\begin{array}{l}\text { Proposed neotype (Sneath, } \\
\text { 1956) TWT }\end{array}$ \\
\hline 45 & 9694 & $\begin{array}{l}\text { Chromobacterium violaceum nom. prop. conserv. } \\
\text { T.Sp. (Sneath, 1956) (C. janthinum) } \ddagger\end{array}$ & - \\
\hline 46 & 9742 & $\begin{array}{l}\text { Chromobacterium iodinum Davis } 1939 \text { (Pseudomonas } \\
\text { iodinum) } \dagger\end{array}$ & Holotype \\
\hline 47 & 4636 & Proteus vulgaris T.Sp. & - \\
\hline 48 & 235 & Proteus morganii & Cotype TWT \\
\hline 49 & 3708 & Loefflerella mallei T.Sp. (Actinobacillus mallei) & TWT \\
\hline 50 & 9796 & Chromobacterium lividum (C. violaceum) $\ddagger$ & $\begin{array}{l}\text { Proposed neotype (Sneath, } \\
\text { 1956) TWT }\end{array}$ \\
\hline 51 & 8545 & Pseudomonas diminuta (Leifson \& Hugh, 1954)* & Paratype \\
\hline 52 & 3984 & Corynebacterium diphtheriae T.Sp. (type gravis) & TWT \\
\hline $\mathbf{5 3}$ & 7429 & Corymebacterium diphtheriae T.Sp. (Park 8 strain) & - \\
\hline 54 & 8151 & Mycobacterium phlei & TWT \\
\hline 55 & 4524 & Nocardia farcinica T.Sp. & Cotype \\
\hline 56 & 8036 & Jensenia canicruria (Bisset \& Moore, 1950)* & Holotype \\
\hline 57 & 7762 & Spirillum rubrum (Rhodospirillum rubrum) T.Sp. & Cotype \\
\hline 58 & 9582 & Spirillum mancuniense (Cayton \& Preston, 1955)†* & Holotype \\
\hline 59 & 8069 & Streptobacillus moniliformis T.Sp. & TWT \\
\hline 60 & 404 & Kurthia zopfii T.Sp. & TWT \\
\hline $\begin{array}{l}* \text { Not } 1 \\
+ \text { Not } 1 \\
\ddagger \text { The }\end{array}$ & $\begin{array}{l}\mathrm{d} \text { in } B e \\
\mathrm{~d} \text { in th } \\
\text { usion } o\end{array}$ & $\begin{array}{l}\text { Manual, 7th edition (1957). } \\
\text { logue of the Collection. } \\
\text { e name Chromobacterium violaceum is because in th } \\
\text { osals have been made (Sneath, 1956) to regularize } \\
\text { ty type strain used in this study and suggested for }\end{array}$ & positio \\
\hline
\end{tabular}

\section{Features}

The features and standard techniques are not listed here in view of the preliminary nature of this work, and since it has been concluded (Sneath, $1957 b$ ) that any large set of features is likely to yield much the same taxonomic conclusions. These details would of course have to be included if a redescription of the taxa were attempted. However, the scope of the features used was as wide as possible, and these were derived from observations on morphology, 
Table 2. Systematic position of the organisms in the classification of Bergey's Manual, 7th edition (1957)

Only the more important taxonomic ranks are given, and heavy type indicates that the taxon is the acce nomenclatural type of the next higher taxon. Names in brackets are those used in Table 1 if they are diff from those in Bergey's Manual. Species marked with an asterisk are not listed in Bergey's Manual and been inserted in the positions implied by their names or by the authors describing them (not necessarily $i$ taxonomically correct positions).

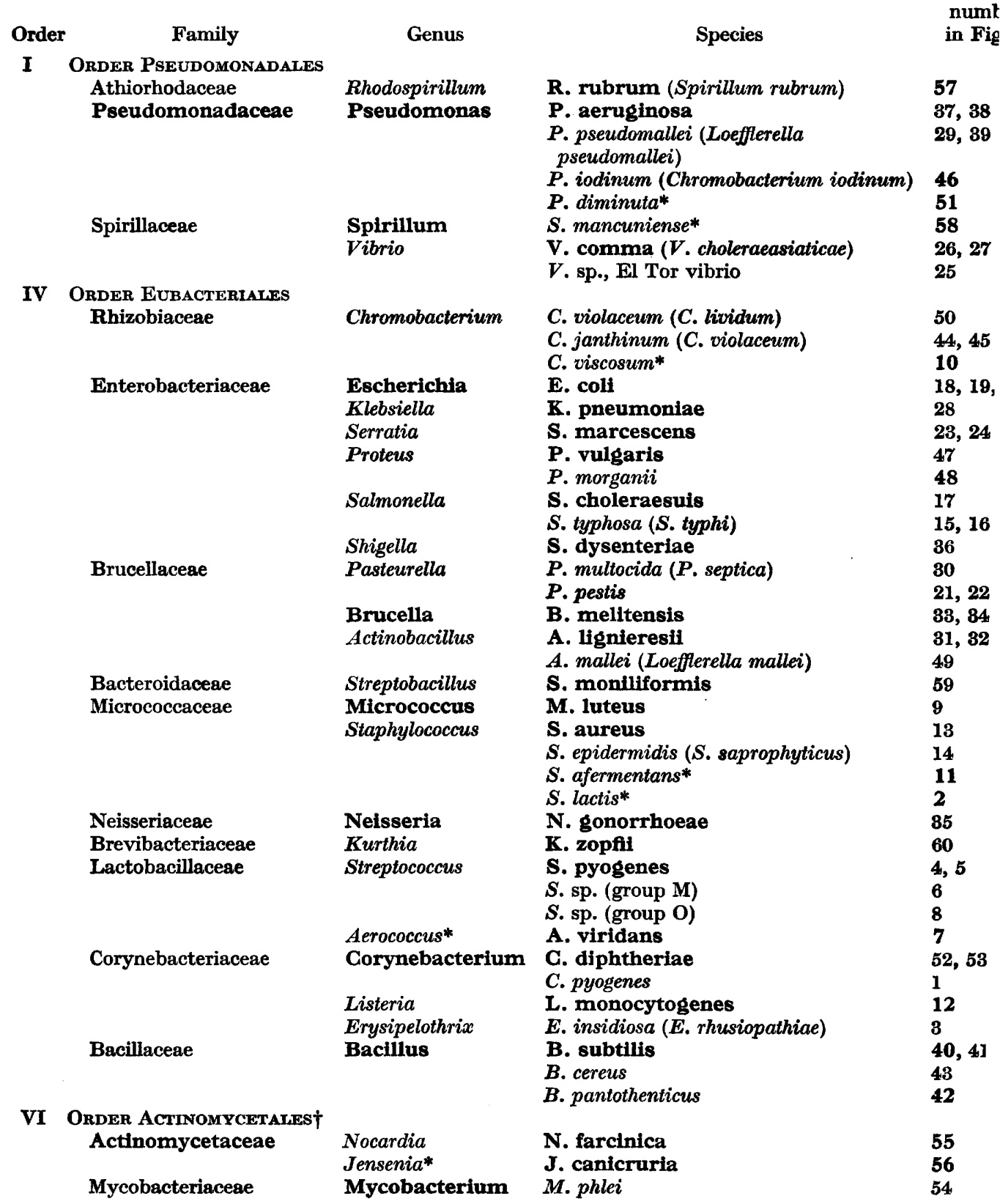

$\dagger$ This Order is correctly Order VI not V-see footnote in Bergey's Manual, 7th edition, Contents, p. 
staining reactions, colonial form, requirements with respect to oxygen, temperature, certain growth factors, etc., acid production from carbohydrates and other biochemical reactions. The number of features used was 134, but for most strains over half were not recorded. The $S$ values are therefore based on fractions in which the term $\left(n_{s}+n_{d}\right)$ is usually 30-50. Features based on antigenic structure and on pathogenicity were omitted since the data on these were fragmentary.

\section{Processing of data}

The data were coded and analysed on the Elliott 402 Electronic Digital Computer (Elliott Bros., Boreham Wood, Hertfordshire) using the 402 Programme 'Bacterial Classification Mark I'. The results are shown in the diagram (Fig. 1) in which the $S$ values have been shaded; this is accurate enough for the present purpose and is easier to see than entries in figures.

The data on the strains were fed into the computing machine in a random order as a check upon the sorting procedure (steps 5-8 in Sneath 1957 b, p. 209). This was only partly successful. Although most of the groups were correctly formed, the order in which these groups were placed was not wholly satisfactory, largely because most of the groups fused together in a very limited range of highest intergroup $S$ values around $70 \%$. Also, several aberrant strains belonging to the main groups were placed at the bottom of the table. On preparing a shaded diagram similar to Fig. 1, it was clear that some rearrangement was necessary. For example, the acid-fast bacilli (nos. 54, 55) were sandwiched between Gram-negative bacteria, and could be seen to be misplaced because of the pale band which they made through that part of the diagram which indicated comparisons between them and the Gram-negative bacteria: this indicated low similarity with the Gram-negative bacteria. Similarly no. 8, a streptococcus, was placed among the Gram-negative bacteria, and this was also a misplacement, as was shown by a dark band across the left-hand side of the diagram (indicating high similarity with other Grampositive bacteria) and a pale band across the right-hand side (indicating low similarity with Gram-negative bacteria).

The table was therefore rearranged, and although this is to some extent an arbitrary step, it rests on the rational basis that mean $S$ values between groups of strains are best for obtaining a satisfactory order of the groups; the sorting procedure employs the highest $S$ values for determining the order only because this is mathematically a simpler procedure. It is perhaps not surprising that some rearrangement was needed with such a varied collection of strains. It is not possible to arrange such a collection in a perfect order, since relations between organisms are multidimensional, as has been pointed out in the description of this method. The organisms nos. 1-3 have been placed on the extreme top and left owing to their closer similarity to Gram-positive organisms than to the Gram-negative. The order given by the sorting procedure is given in the legend to Fig. 1. The rearranged table is shown diagrammatically in Fig. 1, and this forms the basis for the section on Results. The figure is shaded at $10 \%$ levels of $S$, which is as close as is justified, since the error of an individual $S$ value is at least $\pm 10 \%$. 


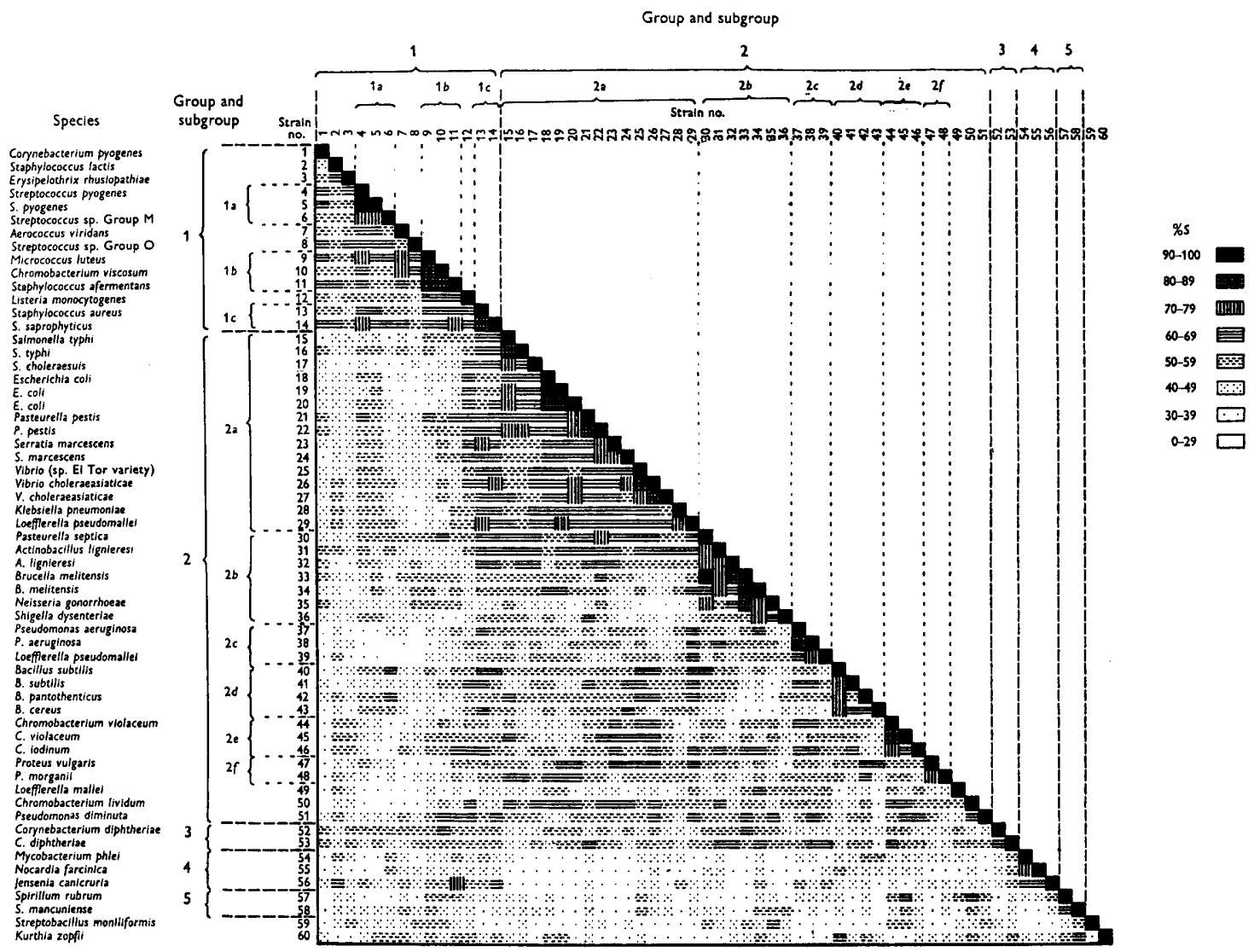

Fig. 1. Diagrammatic representation of the $S$-value table, prepared by shading the squares according to the $S$-values between the strains.

The order of strains given by the sorting procedure was as follows : $4,5,6,9,11,10,7,13$, $14,18,19,20,15,16,21,22,23,24,33,34,35,32,30,31,17,25,26,27,56,28,29,36,37$, $38,39,40,41,42,43,1,54,55,44,45,46,47,48,12,49,50,57,58,51,2,8,52,53,59,3,60$. This order has been somewhat rearranged as is mentioned in the text.

\section{RESULTS}

\section{Chief features of Fig. 1}

Main groups. There are two large groups deliminated by values of $S$ in the region 50-70\%, group 1, consisting predominantly of non-motile Grampositive organisms (nos. 1-14) and group 2, consisting predominantly of Gram-negative organisms (nos. 15-51). In addition there are three small groups of strains, group 3 comprising Corynebacterium diphtheriae (nos. 52, 53), group 4 containing the acid-fast bacteria (nos. 54-56) and group 5 containing spirilla (nos. 57, 58). None of these five groups is very closely similar to any other. The remaining two strains, Streptobacillus moniliformis (no. 59) and Kurthia zopfii (no. 60) may represent distinct groups of their own. 
Subgroups. Within group 1 are three subgroups, subgroup 1 a consisting of several streptococci (nos. 4-6), subgroup $1 b$ (nos. 9-11) containing two micrococci and surprisingly also a diphtheroid organism and subgroup $1 c$ (nos. 13, 14) containing Staphylococcus aureus and $S$. saprophyticus (the latter species contains most of the organisms known to medical bacteriologists as $S$. albus). The other organisms of group 1 do not form clear-cut subgroups: these are Corynebacterium pyogenes, Erysipelothrix rhusiopathiae, Listeria monocytogenes, Staphylococcus lactis, Aerococcus viridans and a group $\mathbf{O}$ streptococcus. They may be subgroups of their own, or may be intermediate forms between other subgroups. There is some overlap between the staphylococci in subgroup $1 c$ and the Gram-negative group 2.

Within group 2 is a large subgroup, $2 a$, containing many of the enterobacteria (nos. 15-29), but excluding Shigella dysenteriae and Proteus. It is divided somewhat indistinctly probably because of the small number of features employed, into sections such as Escherichia, Salmonella and Vibrio. Subgroup $2 a$ also contains Pasteurella pestis. It overlaps with subgroup $2 b$ (nos. 30-36) consisting of Actinobacillus lignieresi, Pasteurella septica, Brucella melitensis and Neisseria gonorrhoeae and perhaps also Shigella dysenteriae type 1 (Shiga's bacillus). The last-named shows little affinity to strains of subgroup $2 b$ and may perhaps rank as a subgroup of its own; it has been shown thus in Fig. 2. Subgroup $2 c$ contains Pseudomonas aeruginosa and one strain of Loefflerella pseudomallei (no. 39). The other strain (no. 29) of the latter organism is placed in subgroup $2 a$, which is a finding we cannot explain. Strain 29, isolated from a sheep, possesses the biochemical properties of a recently isolated strain of Whitmore's bacillus, but is agglutinated only to a low titre by an antiserum known to agglutinate three other strains of Whitmore's bacillus isolated from human cases of melioidosis. Strain 39 is agglutinated to titre by the serum, but has lost a number of biochemical properties, which is a common occurrence on subculturing this organism. Presumably one or the other should be regarded as aberrant, but we cannot say which.

Subgroup $2 d$ (nos. 40-43) contains species of Bacillus. Subgroup $2 e$ (nos. 4446) contains mesophilic strains of Chromobacterium, and also C. iodinum Davis, although this may be a mistake, as the survey of Sneath $(\mathbf{1 9 5 7 b})$ did not indicate such a close relationship. Subgroup $2 f$ (nos. 47, 48) contains species of Proteus. Strains of group 2 which appear to be unlike all other strains of group 2 are nos. 49-51. They are a psychrophilic strain of Chromobacterium, the glanders bacillus and Pseudomonas diminuta. They presumably represent separate subgroups of group 2.

There are insufficient strains of groups 3-5 to reveal subgroups, but some relations to other groups may be mentioned. The two strains of Corynebacterium diphtheriae (group 3, nos. 52, 53) appear to be intermediate between groups 1 and 2, though not closely similar to either. The high value for the comparison between Jensenia canicruria (no. 56) and Staphylococcus afermentans (no. 11) appears to be fortuitous, since Jensenia is not very similar to any other strain of group 1 . It has been placed in group 5 , since it seems closer 
to the acid-fast bacteria; it may perhaps be a form connecting the acid-fast and the Gram-positive bacteria. Two strains of Clostridium were also analysed, but they are not included since, being obligate anaerobes, they could not be validly compared with the other strains. However, they did not show a close similarity to any of the other strains or to one another. The two strains were Clostridium butyricum NCTC 7423 and C. botulinum NCTC 7272.

\section{Summarizing the figure into a taxonomic tree}

It is not possible to express all the relations indicated in Fig. 1 in the few dimensions of a taxonomic tree, and it is doubtful whether the data used here would justify any very elaborate taxonomic tree. Only a rough figure (Fig. 2) is given which shows the main outlines of the classification which is indicated by this study. This figure was drawn from the results of taking mean $S$ values of the groups and subgroups in the same way as in the previous survey (Sneath, $1957 b)$.

\section{Comparison with other surveys}

We can compare the results of two surveys if we have a number of strains which were used in both surveys, and it is then possible to calibrate roughly one $S$ value scale with the other. A crude but simple method for doing this is shown in Table 3 and Fig. 3, which relate the present survey with that of

\section{Table 3. Comparison of $\mathrm{S}$ values in troo surveys}

The $S$ values for comparisons between strains used in both surveys are tabulated below. Table $3 a$ shows the $S$ values found in the present survey, and Table $3 b$ shows those found in the survey of Sneath $(1957 b)$. The strain numbers are those used in the present paper.

(a) $\% S$ values found in the present survey

\begin{tabular}{|c|c|c|c|c|c|c|c|c|}
\hline \multirow{2}{*}{$\begin{array}{c}\text { Strain } \\
\text { number }\end{array}$} & \multicolumn{8}{|c|}{ Strain number } \\
\hline & 10 & 23 & 24 & 38 & 44 & 45 & 46 & $\mathbf{5 0}$ \\
\hline 10 & 100 & & & & & & & \\
\hline 23 & 50 & 100 & & & & & & \\
\hline 24 & 54 & 77 & 100 & & & & & \\
\hline 38 & 44 & 58 & 47 & 100 & & & & \\
\hline 44 & 55 & 60 & 56 & 67 & 100 & & & \\
\hline 45 & 58 & 62 & 62 & $\mathbf{5 5}$ & 82 & 100 & & \\
\hline 46 & 59 & 60 & 54 & 67 & 78 & 63 & 100 & \\
\hline 50 & 50 & 61 & 61 & 58 & 65 & 63 & 59 & 100 \\
\hline
\end{tabular}

(b) $\% S$ values found in survey of Sneath $(\mathbf{1 9 5 7} b)$

\begin{tabular}{|c|c|c|c|c|c|c|c|c|}
\hline \multirow{2}{*}{$\begin{array}{c}\text { Strain } \\
\text { number }\end{array}$} & \multicolumn{8}{|c|}{ Strain number } \\
\hline & 10 & 23 & 24 & 38 & 44 & 45 & 46 & 50 \\
\hline 10 & 100 & & & & & & & \\
\hline 23 & 32 & 100 & & & & & & \\
\hline 24 & 33 & 95 & 100 & & & & & \\
\hline $\mathbf{3 8}$ & 38 & 50 & 54 & 100 & & & & \\
\hline 44 & 43 & 63 & 62 & 57 & 100 & & & \\
\hline 45 & 38 & 57 & 54 & 47 & 82 & 100 & & \\
\hline 46 & 63 & 30 & 29 & 39 & 34 & $\mathbf{3 1}$ & 100 & \\
\hline 50 & 33 & 44 & 41 & 56 & 49 & 42 & 29 & 100 \\
\hline
\end{tabular}


Sneath $(1957 b)$. It is seen from Fig. 3 that the main distortion between the two $S$ value scales lies in the region $30-70 \%$.

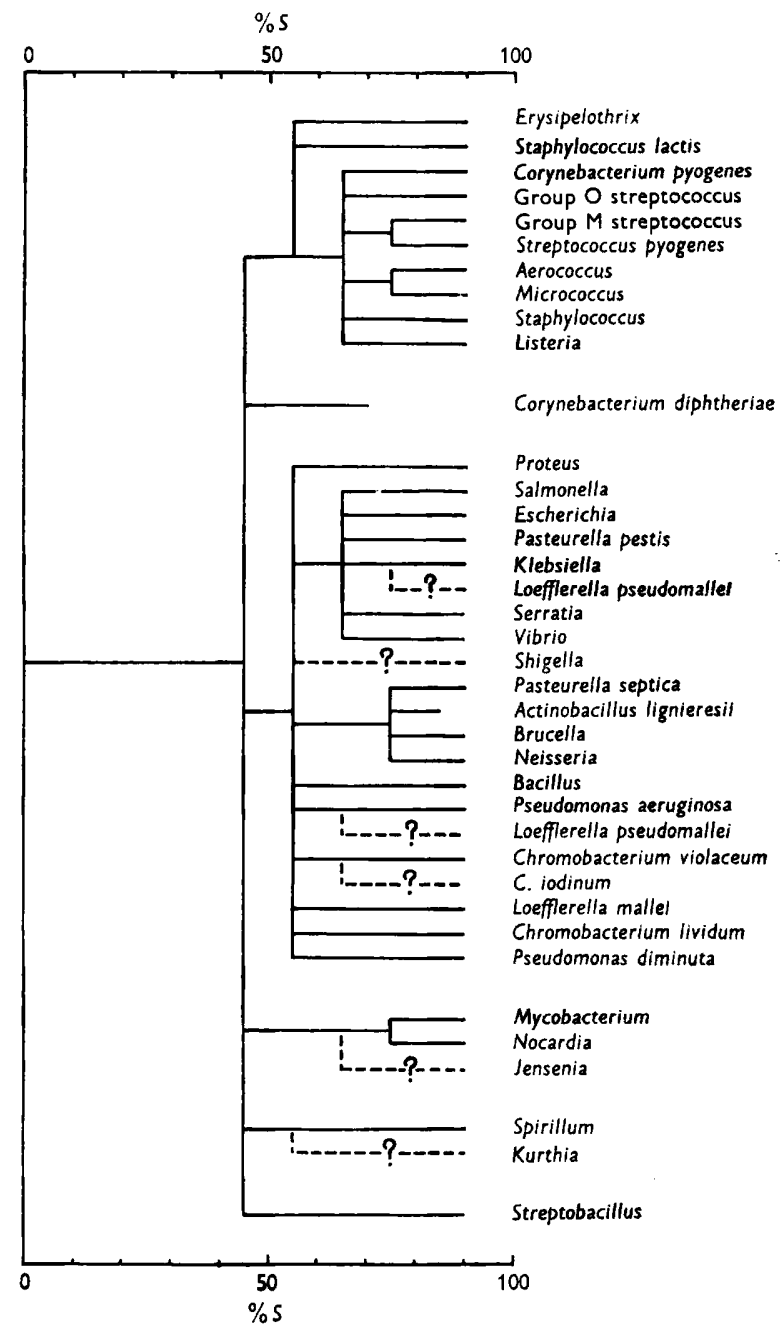

Fig. 2. Taxonomic tree showing the main outlines of the classification suggested by this study.

\section{DISCUSSION}

Limitations of the present survey

Old laboratory records are clearly not as reliable as data from a set of tests put up at one time and compared with one another by a single observer. In the records used here it was noted that there were generally some discrepancies in the features recorded at different examinations of a strain, due presumably to slight differences in media, technique and scoring of the results, but since the Collection consists of freeze-dried cultures there were few changes due to 
variation on subculture. The number of discrepancies suggests that there is an experimental error of at least $5 \%$ in scoring the features used for the analysis. Therefore, the $S$ values cannot be relied upon within $10 \%$ either way. This error could be virtually eliminated by more careful taxonomic study.

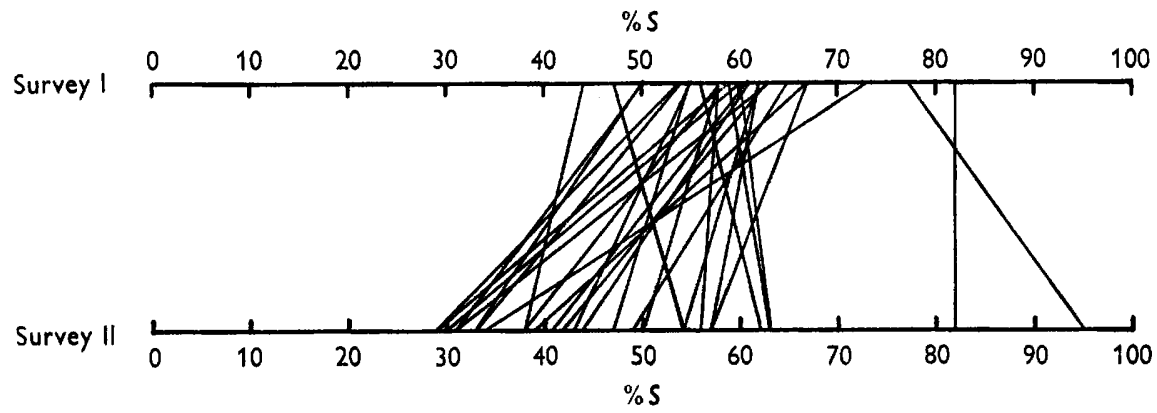

(a) Method of calibration. A line is drawn from the $S$ value found in one survey for the comparison of a particular pair of strains to the $S$ value found in the other survey for the comparison of the same pair of strains (see Table 8). All the comparisons which were made in both surveys are similarly entered.

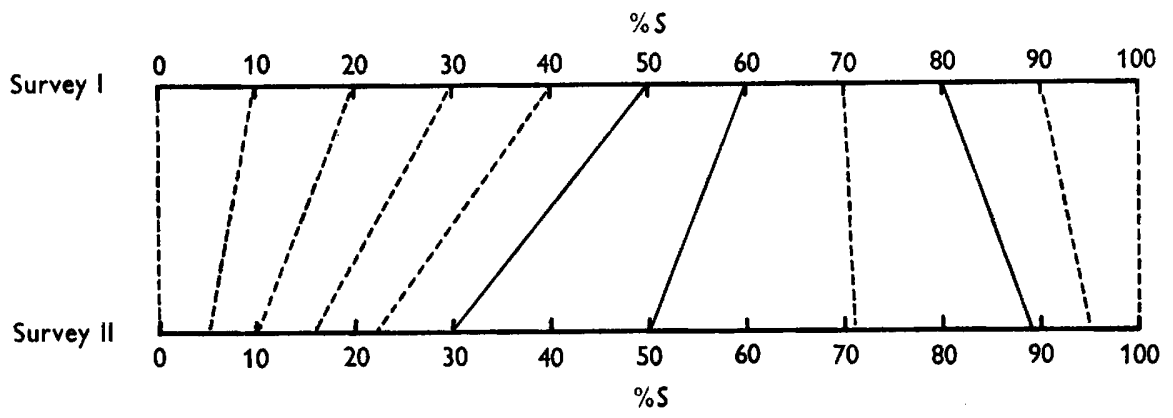

(b) The approximate mean correspondence between the two scales of $S$ is obtained by drawing lines from one scale to the other based on the mean slopes of the lines in figure $3(a)$. The $S$ values of 0 and $100 \%$ are the same on both scales. Endashed lines are only presumptive, as they are not based on information in figure $3(a)$.

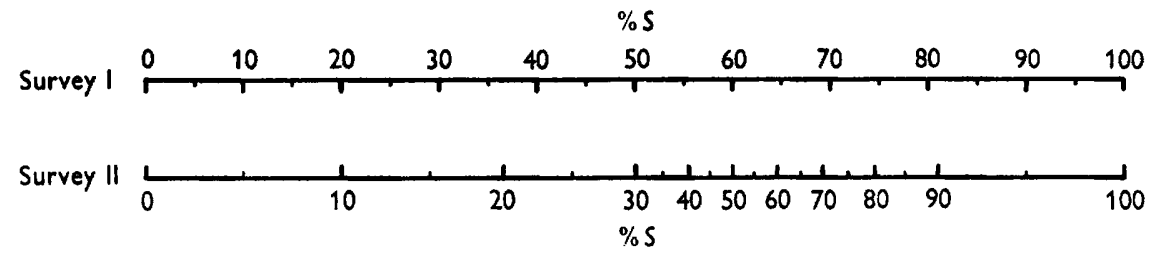

(c) From figure $3(b)$ the two scales are calibrated against each other by distorting one of them.

Fig. 3. Calibration of the $S$ value scale of the present survey (I) with that of the survey of Sneath (1957b) (II).

There is also the 'error' which is due to the fact that even in the most homogeneous groups of organisms there is some variation in features from strain to strain. Some strains will therefore show higher $S$ values than others when they are compared with a strain from another homogeneous group. This is 
probably the explanation for the high $S$ value for the comparison between Jensenia canicruria and Staphylococcus saprophyticus.

Yet another cause of error arises because in a collection of diverse bacteria some groups are routinely examined by certain tests but not by others. Thus, the enterobacteria had usually been examined for amino acid decarboxylases but not for haemolysins, while streptococci had been tested for haemolysins but not for decarboxylases. This would cause some discrepancies between the results obtained here and those which would have been obtained if both groups had been tested in both sets of tests (as would be ideal), although there are reasons for believing that the discrepancies would not be large. The effect of this cause of error is to produce slightly different $S$-value scales for the different groups, and, as can be seen from Fig. 3, while the general conclusions on relations between taxa would be little affected, there might be significant discrepancies in the taxonomic rank and in the relations of individual strains.

For these reasons we do not propose any taxonomic revisions on the results described here, and regard the latter only as pointers for more detailed work. For such work a much greater number of features will be needed to obtain a sound basis for bacterial taxonomy.

\section{The taxonomic arrangement suggested by this study}

The results of this study may be compared with a conventional classification by comparing Fig. 2 with Table 2 . Those who have studied the Gram-positive cocci will not be surprised to find such a high similarity between streptococci, micrococci and some diphtheroids, but it is unexpected that Bacillus is placed with the Gram-negative organisms. The closeness of Pasteurella septica, Brucella, Neisseria and Actinobacillus lignieresi to the typical enterobacteria, and the dissimilarity of Proteus are also unexpected.

The strain of Spirillum rubrum is believed to be the original strain of Esmarck. Whether it was capable of photosynthesis when first isolated is not known, but if so the similarity to $S$. mancuniense suggests that there may be a close relation between the spirilla and the Athiorhodaceae, in which $S$. rubrum is now commonly placed (under the name Rhodospirillum rubrum (Esmarck) Molisch).

The only representative of the genus Shigella which was studied was Shiga's bacillus which is probably the least typical of all shigellas although it is the type species. It is catalase-negative, grows more feebly and is less active biochemically than the other members (serotypes) of the genus. This may explain why Shigella, in this survey, is not as closely related to Escherichia as would be expected on other grounds. Proteus spp. have several features not often found in the Enterobacteriaceae but two of these, gelatinase production and swarming, are easily lost on subculture. Thus the old stock culture of a Proteus species more closely resembles other enterobacteria than do freshlyisolated strains.

\section{Taxonomic rank}

It is clear that there are discrepancies between the rank indicated by the $S$ values and current usage. For example, Salmonella, Escherichia and Vibrio 
seem to be of lower rank than Streptococcus and Bacillus. If the latter are retained as genera the former should logically be reduced to the rank of species; alternatively, Streptococcus and Bacillus could be subdivided into several genera. There can be no absolute criterion of taxonomic rank (as one man's meat is another's poison, so a genus to one will be a family to another), but if certain examples of rank are defined, others can be adjusted to be in harmony. Agreement will not be reached unless rank is assessed on a quantitative basis (whether by the methods used here or by others) and international agreement will be necessary for this.

\section{Divisions into taxa}

Tables of $S$ values do not afford a good guide to whether the strains fall into clear-cut taxa without intermediate forms, since correlations between features (upon which clear-cut taxa are based) may be obscured by the effect of features which are variable from strain to strain. The correlations can be found by examining the original table of strains versus features. This is outside the scope of the present survey, but it may be noted that strains of group 1 generally are non-motile, Gram-positive, coccoid, penicillin-sensitive, seldom produce gas from glucose and have complicated requirements for growth factors, while strains of group 2 generally show the opposite characteristics.

The results suggest that it might be profitable to study the streptococci, micrococci and diphtheroid bacilli as a whole, rather than as separate genera, and also to include genera such as Pasteurella and Vibrio in surveys of the enterobacteria. In an intensive study of a particular group it would help to keep the taxonomy of bacteria in perspective (by providing criteria for higher ranks) if a few standard strains from several of the main groups were included. By limiting their objectives taxonomists have often failed to see the wood for the trees; for instance it is only recently that the similarity between Corynebacterium pyogenes and streptococci has become apparent (Cummins \& Harris, 1956), a relation which this survey has confirmed.

It is well known in biology that a group of organisms can be sorted or arranged in many ways, and like anything else which is essentially a matter of arrangement, the arrangements cannot be true or false but only more convenient or less convenient for specified purposes. For 'general purposes' a 'general classification' is required, which Adansonian principles will provide. Such general classifications cannot be perfect for special purposes. Orthodox taxonomy is in its basic concepts a 'general classification for general purposes'. The example given here shows how progress can be made on these lines in bacterial taxonomy.

\section{REFERENCES}

Ainsworth, G. C. \& Bissy, G. R. (1945). A Dictionary of the Fungi, p. 328, 2nd ed. Kew: Imperial Mycological Institute.

Bergey's Manual of Determinative Bacteriology (1957). 7th ed. Edited by R. S. Breed, E. D. G. Murray and N. R. Smith. London: Ballière, Tindall and Cox. 
Bisset, K. A. \& Moone, F. W. (1950). Jensenia, a new genus of the Actinomycetales. J.gen. Microbiol. 4, 280.

BreEd, R. S. (1952). The type species of the genus Micrococcus. Internat. Bull. bact. Nomen. Tax. 2, 85.

Cayton, H. R. \& Preston, N. W. (1955). Spirillum mancuniense n.sp. J. gen. Microbiol. 12, 519.

Ciferri, R. (1957). Type nomenclature of micro-organisms in culture. G. Microbiol. 4, 31.

Cowan, S. T., Shaw, C. \& Williams, R. E. O. (1954). Type strain for Staphylococcus aureus Rosenbach. J. gen. Microbiol. 10, 174.

Cummins, C. S. \& Harris, H. (1956). The chemical composition of the cell wall in some Gram-positive bacteria and its possible value as a taxonomic character. J. gen. Microbiol. 14, 583.

Davis, J. G. (1939). Chromobacterium iodinum (n.sp.). Zbl. Bakt. (Abt. 2), 100, 273.

GrIMEs, M. (1927). An aerobic capsulated bacterium chromogenic on sugar media. Zbl. Bakt. (Abt. 2), 72, 367.

International Code of Nomenclature of Bacteria and Viruses (1958). Edited by R. E. Buchanan, S. T. Cowan, T. Wikén and W. A. Clark. Ames, Iowa: Iowa State College Press.

Leifson, E. \& Hugh, R. (1954). A new type of polar monotrichous flagellation. J. gen. Microbiol. 10, 68.

The National Collection of Type Cultures: Catalogue of Species. (1958). Medical Research Council Memorandum No. 35. London: Her Majesty's Stationery Office.

Shaw, C., StitT, J. M. \& Cowan, S. T. (1951). Staphylococci and their classification. J. gen. Microbiol. 5, 1010.

SNeAth, P. H. A. (1956). Conservation of the generic name Chromobacterium and designation of type species and type strains. Internat. Bull. bact. Nomen. Tax. $6,65,157$.

SNeAth, P. H. A. (1957 a). Some thoughts on bacterial classification. J. gen. Microbiol. 17, 184.

SNeath, P. H. A. $(1957 b)$. The application of computers to taxonomy. $J$. gen. Microbiol. 17, 201.

St John-Brooks, R. \& Breed, R. S. (1937). Actions taken by the Second International Microbiological Congress in London, 1936, regarding bacteriological nomenclature. J. Bact. 33, 445.

Williams, R. E. O., Hirch, A. \& Cowan, S. T. (1953). Aerococcus, a new bacterial genus. J. gen. Microbiol. 8, 475 .

(Received 9 June 1958) 